\title{
QUALIDADE FÍSICA E FISIOLÓGICA DAS CIPSELAS DE Piptocarpha angustifolia Dusén ex Malme DE DIFERENTES POPULAÇÕES E ÁRVORES PORTA-SEMENTES
}

\author{
Luiz Cláudio Fossati ${ }^{1}$, Antônio Carlos Nogueira ${ }^{2}$ \\ ${ }^{1}$ Eng. Florestal, Dr., Universidade do Contestado, Canoinhas, SC, Brasil - lfossati@ cni.unc.br \\ ${ }^{2}$ Eng. Florestal, Dr., Depto. de Ciências Florestais, UFPR, Curitiba, PR, Brasil - nogueira@ufpr.br \\ Recebido para publicação: 27/02/2008 - Aceito para publicação: 10/09/2008
}

\begin{abstract}
Resumo
Este trabalho teve como objetivo determinar a influência de diferentes populações e árvores portasementes na qualidade física e fisiológica das sementes de Piptocarpha angustifolia (vassourãobranco). Selecionaram-se três populações no planalto norte de Santa Catarina, Brasil, coletando-se as cipselas de doze árvores porta-sementes por população. Avaliou-se pureza, umidade, peso, dimensões, germinação, emergência e vigor das cipselas. Os ensaios obedeceram a um delineamento inteiramente casualizado em arranjo fatorial de forma hierárquica. As diferenças entre populações e árvores porta-sementes foram testadas pela ANOVA, e as médias submetidas ao teste de Tukey e Scott-Knott. Foram necessárias amostras de trabalho de 1,29 g de cipselas para o teste de pureza. A espécie possui em média 1.545 .104 cipselas. $\mathrm{kg}^{-1}$, diferindo entre árvores porta-sementes. As cipselas medem, em média, 0,62 $\mathrm{mm}$ de largura, 3,26 $\mathrm{mm}$ de comprimento e $0,58 \mathrm{~mm}$ de espessura, dimensões que diferem conforme a árvore porta-sementes. A germinação é de 5,64\%, independentemente da árvore porta-sementes e da população. O tempo médio de germinação é de 25 dias, diferindo entre árvores porta-sementes. A emergência média de 5,28\% independe de populações e árvores porta-sementes. O tempo médio de emergência é de 71 dias, que difere entre árvores portasementes.

Palavras-chave: Sementes florestais; germinação; emergência; vigor; vassourão-branco.
\end{abstract}

\begin{abstract}
Physical and physiological quality of Piptocarpha angustifolia Dusén ex Malme seeds in differents populations and seed-bearer trees. The objective of this research work was to determine the influence of different populations and seed-bearer trees on the physical and physiological quality of Piptocarpha angustifolia (vassourão-branco) seeds. There were selected three populations in the Santa Catarina north plateau, Brazil, collecting the seeds of twelve seed-bearer trees by population. Were evaluated the purity, humidity, weight, dimensions, germination, emergence and vigor of seeds. The tests followed a randomized entirely design in factorial arrangement of hierarchical order. The differences between populations and seed-bearers trees were tested by ANOVA and averages examined by Tukey and Scott \& Knott tests. They were necessary samples 1,29 g of seeds to the purity test; the species has 1.545 .104 seeds. $\mathrm{kg}^{-1}$, differing between seed-bearer trees; the seeds measuring $0,62 \mathrm{~mm}$ wide, $3,26 \mathrm{~mm}$ long and $0,58 \mathrm{~mm}$ thick, sizes with differ according to seedbearer trees; germination of $5,64 \%$ independent of seed-bearer trees and populations; mean germination of 25 days, which differ between seed-bearer trees; emergence average of 5,28\%, independent of populations and seed-bearer trees; average time of emergence of 71 days, which differ between seed-bearer trees.

Keywords: Forest seeds; germination; emergence; vigor; vassourão-branco.
\end{abstract}

\section{INTRODUÇÃO}

Apesar de ser um dos principais polos da produção florestal do Brasil, o planalto norte do estado de Santa Catarina destaca-se pela produção primária, abastecendo a indústria de baixa agregação de valor no fornecimento de matéria-prima. A cadeia produtiva regional necessita diversificar a produção florestal 
para abranger atividades de maior densidade econômica e gerar mais emprego e renda, pois a região é uma das mais carentes do estado. Nesse contexto, a Agência de Desenvolvimento Regional Integrado do Planalto Norte Catarinense (ADR-Plan) definiu a necessidade de viabilizar uma alternativa para a produção de madeira na região, determinando a necessidade de geração de conhecimento sobre as espécies florestais nativas da região que sejam potenciais para produção de madeira, excetuando-se as já consagradas Araucaria angustifolia (Bert.) O. Ktze. (araucária), Mimosa scabrella Benth. (bracatinga) e Cedrela fissilis Vell. (cedro). As pesquisas necessárias devem dar prioridade, entre outras espécies, para Piptocarpha angustifolia Dusén ex Malme (vassourão-branco), devido às suas características ortotrópicas, rápido crescimento, madeira de qualidade para diversos fins e histórico favorável de desdobro e beneficiamento na indústria local.

Além das justificativas do ponto de vista da produção de sementes florestais nativas para fins madeireiros, é imprescindível mencionar que a espécie indicada constitui-se em importante elemento da restauração de áreas degradadas. O seu plantio é recomendado na recomposição de ecossistemas naturais alterados nas áreas de preservação permanente e de reserva legal, da mesma forma demandando pesquisas, visando melhorar a qualidade das sementes para esse fim.

Conhecida como vassourão-branco, vassourão ou vassourão-cavalo, Piptocarpha angustifolia Dusén ex Malme (Asteraceae) é uma árvore de 15 a 25 m de altura quando adulta, com tronco liso de 30 a $40 \mathrm{~cm}$ de diâmetro, folhas simples, glabras na face superior e densamente pubescentes na inferior, de $7 \mathrm{a}$ $9 \mathrm{~cm}$ de comprimento por 7 a $15 \mathrm{~mm}$ de largura, inflorescências em capítulos axilares, solitários ou em grupos de dois ou três, com seis a oito flores de cor paleácea. Planta perenifólia, heliófita e seletiva higrófita, característica das submatas que tenham sofrido acentuada interferência humana pela extração de madeiras, a espécie é, portanto, típica de formações secundárias, principalmente as situadas em vales e encostas úmidas. Árvore monóica, produz anualmente grande quantidade de sementes facilmente disseminadas pelo vento. Ocorre de São Paulo ao Rio Grande do Sul, na floresta semidecídua de altitudes e matas de pinhais. A madeira é leve, macia, de tecido frouxo, pouco resistente, de baixa durabilidade natural, com alburno e cerne praticamente indistintos. Pode ser empregada para usos internos em construção civil, para produção de chapas de madeira compensada e aglomerados e para lenha. A árvore de copa prateada é bastante ornamental e pode ser empregada na arborização em geral. Planta de rápido crescimento, é ótima para plantios mistos destinados à recomposição de áreas degradadas de preservação permanente. Floresce durante os meses de outubro a janeiro, e os frutos amadurecem nos meses de novembro a fevereiro. Os frutos são colhidos diretamente da árvore quando iniciam a dispersão. Para facilitar a operação, cortam-se as infrutescências, que são levadas ao sol para secar e liberar as sementes. Devido à facilidade com que são levadas pelo vento, é necessário cobri-las durante a secagem em peneiras (LORENZI, 2001; REITZ et al., 1979; REITZ et al., 1983; INOUE et al., 1984).

Para essa espécie, é difícil distinguir o que é fruto e o que é semente do ponto de vista botânico. Alguns frutos são comumente denominados de "sementes", porém, ao se observar cuidadosamente seu completo desenvolvimento e estudar detalhadamente sua estrutura, percebe-se que a semente vem acompanhada de outras estruturas de proteção ou de dispersão, que não são separadas na propagação (FLOSS, 2004). Por esse motivo, a unidade de dispersão de Piptocarpha angustifolia é chamada de cipsela, que é o conjunto do fruto, que pode conter ou não a semente aderida, e as "franjas" de disseminação chamadas de pápus, forma em que são colhidas e utilizadas para propagação (SEITZ, 1976).

Para o desenvolvimento silvicultural sustentável dos plantios, é necessário minimizar as deficiências existentes na disponibilidade de informações sobre a produção de sementes de Piptocarpha angustifolia. Dentre outras dificuldades, destaca-se a baixa, lenta e desuniforme germinação e vigor das sementes, diminuindo o rendimento no viveiro e consequentemente desestimulando a produção de mudas e os plantios. A população de origem e a árvore porta-sementes, onde são colhidas as sementes, podem se constituir em fontes de variação da sua qualidade física e fisiológica e contribuir para o entendimento e melhoria desse comportamento.

Diante da demanda considerável em empregar Piptocarpha angustifolia, ampliando sua utilização, foi necessário buscar mais informações para subsidiar o estabelecimento das condições adequadas para a germinação de sementes. Assim, o presente trabalho teve por objetivo determinar a influência de diferentes populações e árvores porta-sementes na qualidade física e fisiológica de suas sementes. 


\section{MATERIAL E MÉTODOS}

\section{Caracterização das populações estudadas}

Foram selecionadas três populações de Piptocarpha angustifolia (vassourão-branco) na região do Planalto Norte Catarinense, em fragmentos remanescentes de Floresta Ombrófila Mista, com pelo menos 200 hectares quase contínuos e representativos, nos municípios de Canoinhas e Três Barras. As populações estão distanciadas de aproximadamente $20 \mathrm{~km}$ entre si e se constituem nos locais de coleta de sementes dessas espécies pelos viveiristas da região. Para efeito deste estudo, as populações foram assim denominadas:

População Canoinhas: propriedades rurais na região dos bairros Boa Vista, Nossa Senhora Aparecida, Morro da Fumaça e Alto do Frigorífico, nos arredores da área urbana, seguindo para o interior nas localidades de Alto da Pedra Branca, Caraguatá, Sereia e Rio do Pinho, todas no município de Canoinhas (SC).

População Marcílio Dias: formada pelas áreas contíguas ao Campus do Setor de Ciências Agrárias da Universidade do Contestado (UnC), no Colégio Agrícola do Centro de Educação Profissional Vidal Ramos (CEDUP) e na futura unidade de conservação da Fundação do Meio Ambiente de Santa Catarina (FATMA), todas no Distrito de Marcílio Dias, Canoinhas (SC).

População Três Barras: Floresta Nacional (Flona) de Três Barras, do Instituto Brasileiro do Meio Ambiente e dos Recursos Naturais Renováveis (Ibama), incluindo a sua área de influência, em Três Barras (SC).

As populações estudadas estão inseridas numa região entre as coordenadas $26^{\circ} 03^{\prime} 43^{\prime \prime} \mathrm{S}$ e $50^{\circ} 16^{\prime} 59^{\prime \prime} \mathrm{W}$ a $26^{\circ} 12^{\prime} 06^{\prime}$ 'S e $50^{\circ} 31$ '39'W. A altitude variou de 772 a $831 \mathrm{~m}$, com relevo suavemente ondulado. O clima regional, de acordo com a classificação de Koeppen, é do tipo $\mathrm{Cfb}$, possui chuvas bem distribuídas ao longo do ano, o que determina uma umidade relativa média em torno de $85 \%$, e precipitação em torno de $1.400 \mathrm{~mm}$ anuais (EPAGRI, 2006). O solo apresenta-se predominantemente como Cambissolo Húmico distrófico típico e léptico, conforme a classificação proposta pela EMBRAPA (1999). A vegetação original da região é classificada, segundo um modelo universal, como Floresta Ombrófila Mista Montana (IBGE, 1992).

\section{Seleção das árvores porta-sementes}

Em cada uma das três populações, foram selecionadas 12 árvores porta-sementes, distantes pelo menos $100 \mathrm{~m}$ uma da outra, de onde foram coletadas as cipselas. O critério adotado para seleção das árvores porta-sementes compreendeu indivíduos produzindo sementes, enquadrados dentro das alturas e diâmetros à altura do peito (DAP) da caracterização média representativa descrita por Rizzini (1971), Seitz (1976), Rotta (1977), Reitz et al. (1979), Reitz et al. (1983), Inoue et al. (1984), Carvalho (1994) e Lorenzi (2001).

\section{Coleta das cipselas}

As cipselas foram coletadas entre 18 de janeiro e 03 de fevereiro de 2006, por equipe treinada do Laboratório de Sementes Florestais da Universidade do Contestado (UnC). Utilizou-se, como critério para coleta, árvores com pelo menos $70 \%$ de seus frutos maduros. As árvores foram escaladas pelo tronco com esporões e talabarte e colhidas com auxílio de podão. Os ramos foram recolhidos em lonas, com retirada das impurezas, e imediatamente acondicionados em sacos plásticos para o transporte. Tomou-se o cuidado de não despojar a planta por completo, procurando coletar no máximo $30 \%$ do total de frutos da árvore. Cada lote foi identificado por uma ficha de coleta contendo os dados da árvore porta-sementes.

Imediatamente após a coleta, os lotes foram etiquetados. As cipselas foram separadas manualmente, primeiro das partículas maiores e em seguida das partículas menores, até a obtenção de uma massa ainda com impurezas, mas de difícil separação. As cipselas foram acondicionadas em embalagens plásticas e, em seguida, armazenadas em câmara fria $\left(4\right.$ a $\left.5^{\circ} \mathrm{C}\right)$ por um período máximo de 25 dias.

\section{Testes de qualidade física das sementes}

Foi realizado o teste de pureza para cada uma das árvores porta-sementes e para cada uma das populações, utilizando-se quatro repetições. Determinou-se o peso de mil sementes, utilizando-se oito repetições de 100 sementes, conforme BRASIL (1992). Calculou-se o coeficiente de variação das 
subamostras e quando este foi maior que 6\%, repetiu-se o teste. Quando ele foi menor que os valores mencionados, multiplicou-se a média das subamostras por 10. Calculou-se o número de sementes por $\mathrm{kg}$ com oito repetições de cada árvore porta-sementes, segundo Oliveira (2007).

Determinou-se o teor de água inicial das sementes de cada uma das árvores matrizes e para cada uma das populações, utilizando-se quatro repetições de $0,07 \mathrm{~g}$ (cadinhos de alumínio com tampa) pelo método da estufa sem circulação de ar a $105^{\circ} \mathrm{C} \pm 2{ }^{\circ} \mathrm{C}$ por 24 horas, conforme Brasil (1992).

A biometria das cipselas foi obtida da medição da largura, comprimento e espessura em milímetros, utilizando-se paquímetro digital com precisão de duas casas, em 4 repetições de 10 sementes retiradas aleatoriamente de cada lote. $\mathrm{O}$ comprimento foi medido no sentido longitudinal da semente, tomando-se a distância entre o extremo hilar e o da chalaza; a largura foi obtida perpendicularmente ao comprimento, considerando-se a face mais larga da semente, o que correspondeu à linha mediana das sementes no sentido da largura dos cotilédones; e a espessura, pela medição também perpendicular ao comprimento, só que na face menos larga da semente, correspondendo a linha mediana, abrangendo os dois cotilédones (KUNIYOSHI, 1983).

\section{Testes de qualidade fisiológica das sementes}

As diferenças entre populações e árvores porta-sementes quanto à germinação e ao vigor foram determinadas por meio de teste de germinação, testando-se os três locais (populações) e 12 árvores portasementes por população. Os resultados foram obtidos de quatro repetições de 50 sementes por árvore porta-sementes, em gerbox colocados no germinador do tipo Mangelsdorf, substrato sobre areia, sob luz artificial constante e temperatura de $25{ }^{\circ} \mathrm{C}$ (BRASIL, 1992). As contagens obedeceram ao ritmo de germinação da espécie, definido pelo acompanhamento diário e tomando-se intervalos curtos até que a curva de germinação se estabilizasse. Foi considerada germinada, para efeito deste estudo, a protrusão da radícula, com no mínimo $0,5 \mathrm{~mm}$ (SCHIMIDT, 2000). Para o cálculo da porcentagem de germinação, foi utilizada a fórmula $G=(N / A)$. 100, conforme Brasil (1992), em que $\mathrm{G}$ é a porcentagem de germinação, $\mathrm{N}$ é o número de sementes germinadas e $\mathrm{A}$ é o número total de sementes colocadas para germinar.

Paralelamente, foi instalado e conduzido um experimento em condições de viveiro, dentro de casa de vegetação (estufa de filme plástico), em sementeiras do tipo caixa de madeira subdivididas em células com capacidade para 50 sementes, substrato solo de floresta da camada superficial peneirada em malha $3 \mathrm{~mm}$, para verificação da porcentagem e velocidade de emergência por população e por árvore porta-sementes. Foi considerada para a contagem da porcentagem de emergência a plântula cuja fase de desenvolvimento se apresentava com raiz, hipocótilo, epicótilo e protofilos (primeiro par de folhas surgido no epicótilo) (KUNIYOSHI, 1983).

Para o cálculo da porcentagem de emergência, foi utilizada a fórmula: $E=\left(N_{e} / A_{e}\right) .100$, em que E é a porcentagem de emergência, $\mathrm{N}_{\mathrm{e}}$ é o número de plântulas emergidas na sementeira e $\mathrm{A}_{\mathrm{e}}$ é o número total de sementes colocadas para emergir.

Para os cálculos de vigor, foram obtidos dados por meio de contagens periódicas dos testes de germinação e emergência. Para o cálculo do Índice de Velocidade de Germinação (IVG), foi usada a fórmula de Maguire (1962), apresentada por Vieira e Carvalho (1994): $I V G=\Sigma P_{i} / D_{i}$, em que IVG é o índice de velocidade de germinação, $\mathrm{P}_{\mathrm{i}}$ é o número de sementes germinadas no i-ésimo dia e $\mathrm{D}_{\mathrm{i}}$ é o número de dias entre o início do teste até o i-ésimo dia. Os cálculos de tempo médio foram realizados conforme fórmula citada por Labouriau e Valadares (1976): $t G=(\Sigma n i t i) / \Sigma n i$, em que tG é o tempo médio de germinação, ni é o número de sementes germinadas no i-ésimo dia e ti é o tempo (dias). Os cálculos de velocidade média foram realizados de acordo com a fórmula citada por Labouriau e Valadares (1976): $V G=1 / t G$, em que VG é a velocidade média de germinação e tG é o tempo médio de germinação. O índice de velocidade de emergência (IVE), o tempo médio e a velocidade média de emergência foram calculados segundo as fórmulas citadas acima.

\section{Delineamento experimental e análise estatística}

Primeiramente, todos as variáveis analisadas foram submetidas ao teste de homogeneidade de variâncias (teste de Bartlett) a 5\% de probabilidade de erro. Quando significativo, foi aplicada a transformação $\sqrt{X+1}$ aos dados em porcentagens e aos que apresentaram valor 0 (zero), e $\sqrt{X}$ para os demais, para permitir a análise de variância (ANOVA).

Os ensaios para verificação das diferenças entre populações e entre árvores porta-sementes, com relação à qualidade física e fisiológica das sementes, obedeceram a um delineamento inteiramente 
casualizado em arranjo fatorial (3 populações x 12 árvores porta-sementes), mas com os fatores arranjados de forma hierárquica (12 árvores porta-sementes dentro de cada uma das 3 populações). As diferenças entre populações, entre árvores porta-sementes dentro de cada população e entre todas as árvores porta-sementes foram testadas pela ANOVA através do Teste "F" a 5\% de probabilidade de erro. Sempre que houve diferença significativa, as médias foram submetidas ao teste de Tukey a $5 \%$ de probabilidade de erro para a diferença entre populações e ao teste de Scott-Knott a 5\% de probabilidade de erro para as diferenças entre árvores porta-sementes dentro de cada população e entre todas as árvores porta-sementes. Em todas as análises de variância, são apresentados nas tabelas o coeficiente de variação (CV\%) de cada conjunto de dados analisados, e sua interpretação nas discussões foi feita com base em Pimentel Gomes (1982). Os cálculos do teste de homogeneidade de variâncias (Bartlett), as análises de variância e os testes de Tukey foram feitos no programa Statistica, e para as análises que exigiram o teste de Scott-Knott foi utilizado o programa Saeg.

\section{RESULTADOS E DISCUSSÃO}

\section{Qualidade física}

A heterogeneidade do resultado do beneficiamento de cipselas de Piptocarpha angustifolia é um reflexo da dificuldade de operacionalização da separação das impurezas do lote, pelo método manual. Estatisticamente, essa afirmação se confirmou, conforme se pode constatar na tabela 1. A pureza dos lotes estudados variou mais de $30 \%$ no geral, obtendo-se uma porcentagem mínima de 27,5\% até um máximo de $71,7 \%$, o que resultou em diferenças significativas entre praticamente todas as médias. Nas populações não foi diferente, com grande estratificação das médias dentro delas, igualmente com grandes coeficientes de variação. Porém entre as populações não houve diferenças estatísticas, com $41,8 \%$ de pureza em Canoinhas, 44,4\% em Marcílio Dias e 42,3\% em Três Barras, o que resultou em uma média geral de $42,9 \%$ de pureza. Ferriani et al. (2005) conseguiram uma pureza de 50,5\% nas sementes de Piptocarpha angustifolia.

A operação de beneficiamento de sementes pequenas, acompanhada de materiais inertes de tamanho, peso e densidade semelhantes, como é o caso das cipselas de Piptocarpha angustifolia, torna-se difícil por meios manuais. Pode-se melhorar o resultado com a utilização de equipamentos como as máquinas de ar e peneiras ou o ventilador vertical (FIGLIOLIA et al., 1993). Na prática, a utilização de tais artefatos ainda não é economicamente viável, devido à inexistência de valor econômico das sementes da espécie e da dificuldade de dispor desses equipamentos e de seus respectivos protocolos de uso. A tarefa, portanto, depende da técnica manual de separação de impurezas, que é uma função direta do grau de pureza que o lote chega da coleta para o beneficiamento, resultando na heterogeneidade observada. Um fator de relevância do ensaio é o grau de pureza em que um lote de cipselas da espécie pode ser aceito para utilização. Carneiro (1986) afirma que valores abaixo de $90 \%$ para espécies com sementes grandes e fáceis de limpar é indício de limpeza malfeita. Porém, em sementes pequenas, com muitas impurezas também de pequenas dimensões, torna-se difícil a definição desses limites. Os procedimentos foram executados observando-se o que prescrevem as Regras para Análise de Sementes (BRASIL, 1992), porém os resultados de porcentagem de pureza dos lotes de sementes de Piptocarpha. angustifolia apresentados possuem importância de caracterização da espécie, pois refletem a variabilidade que elas apresentam. Como foram seguidas as recomendações da RAS (BRASIL, 1992), Silva (1988) e Salomão et al. (2003), é possível atingir as médias apresentadas através de métodos manuais. Pode-se dizer, portanto, que para as cipselas de Piptocarpha angustifolia, no mínimo 30\% de pureza pode ser exigido para se obter um lote com beneficiamento aceitável para a comercialização.

Tanto o peso de mil cipselas como o número de cipselas por quilograma, observados na Tabela 1, apresentaram diferenças significativas dentro de cada população e entre todas as árvores portasementes, mas não foram significativos entre as populações. Em Canoinhas, o peso de mil cipselas variou em média de 0,50 g (1.991.799 cipselas.kg $\left.{ }^{-1}\right)$ a 0,74 $\mathrm{g}$ (1.362.679 cipselas. $\left.\mathrm{kg}^{-1}\right)$; em Marcílio Dias, de 0,55 $\mathrm{g}\left(1.814 .291\right.$ cipselas.kg $\left.{ }^{-1}\right)$ a $0,85 \mathrm{~g}$ (1.176.555 cipselas.kg $\left.{ }^{-1}\right)$; em Três Barras, de 0,55 g (1.835.387 cipselas. $\left.\mathrm{kg}^{-1}\right)$ a $0,84 \mathrm{~g}\left(1.200 .615\right.$ cipselas. $\left.\mathrm{kg}^{-1}\right)$, com médias de $0,65 \mathrm{~g}\left(1.553 .806\right.$ cipselas. $\left.\mathrm{kg}^{-1}\right), 0,66 \mathrm{~g}$ (1.549.050 cipselas.kg $\left.{ }^{-1}\right)$ e $0,67 \mathrm{~g}\left(1.534 .455\right.$ cipselas. $\left.\mathrm{kg}^{-1}\right)$, respectivamente. Portanto, mil cipselas de Piptocarpha angustifolia pesam 0,66 g em média, e em um quilograma são encontradas em média 1.545.104 cipselas. 
Tabela 1. Qualidade física das cipselas de árvores porta-sementes logo após a coleta de populações de Piptocarpha angustifolia no planalto norte catarinense.

Table 1. Physical quality of the seeds of seed-bearer trees soon after the collection of Piptocarpha angustifolia populations in Santa Catarina north plateau.

\begin{tabular}{|c|c|c|c|c|c|c|c|c|}
\hline \multicolumn{2}{|c|}{$\begin{array}{l}\text { Populações e porta- } \\
\text { sementes }\end{array}$} & \multirow{2}{*}{$\begin{array}{c}\begin{array}{c}\text { Pureza } \\
(\%)\end{array} \\
27,5 \text { e } \mathrm{m}\end{array}$} & \multirow{2}{*}{$\begin{array}{c}\begin{array}{c}\text { Peso mil } \\
\text { cipselas } \\
(\mathbf{g})\end{array} \\
0,66 \mathrm{~b} \mathrm{~h}\end{array}$} & \multirow{2}{*}{$\begin{array}{c}\begin{array}{c}\text { Número } \\
\left(\text { cipselas.kg }^{-1}\right)\end{array} \\
1.530 .620 \mathrm{~d} \mathrm{j}\end{array}$} & \multirow{2}{*}{$\begin{array}{c}\begin{array}{c}\text { Teor água } \\
\text { inicial } \\
(\%)\end{array} \\
18,5 \mathrm{~b} \mathrm{~b}\end{array}$} & \multirow{2}{*}{$\begin{array}{c}\begin{array}{c}\text { Largura } \\
(\mathbf{m m})\end{array} \\
0,62 \mathrm{~b} \mathrm{c}\end{array}$} & \multirow{2}{*}{$\begin{array}{c}\begin{array}{c}\text { Compri- } \\
\text { mento } \\
(\mathbf{m m})\end{array} \\
3,18 \mathrm{~b} \mathrm{f}\end{array}$} & \multirow{2}{*}{$\begin{array}{c}\begin{array}{c}\text { Espessura } \\
(\mathbf{m m})\end{array} \\
0,59 \text { a d }\end{array}$} \\
\hline & 1 & & & & & & & \\
\hline & 2 & $41,4 \mathrm{c} \mathrm{k}$ & $0,66 \mathrm{~b} \mathrm{~h}$ & $1.523 .944 \mathrm{e} \mathrm{j}$ & $14,0 \mathrm{~b} \mathrm{~b}$ & $0,68 \mathrm{~b} \mathrm{~b}$ & $3,20 \mathrm{~b} \mathrm{f}$ & $0,64 \mathrm{a} \mathrm{c}$ \\
\hline & 3 & 30,9 e m & $0,59 \mathrm{~d} 1$ & $1.710 .026 \mathrm{~b} \mathrm{e}$ & $16,7 \mathrm{~b} \mathrm{~b}$ & $0,54 \mathrm{c} \mathrm{c}$ & $2,41 \mathrm{~d} 1$ & 0,67 a c \\
\hline $\mathrm{C}$ & 4 & 29,2 e m & 0,74 a f & $1.362 .679 \mathrm{f} 1$ & $12,9 \mathrm{~b} \mathrm{~b}$ & $0,57 \mathrm{~b} \mathrm{c}$ & $2,95 \mathrm{ch}$ & 0,59 a d \\
\hline $\mathrm{a}$ & 5 & $34,8 \mathrm{~d} \mathrm{~m}$ & 0,74 a f & $1.362 .679 \mathrm{f} 1$ & $10,1 \mathrm{~b} \mathrm{~b}$ & $0,73 \mathrm{a} \mathrm{b}$ & $3,34 \mathrm{~b} \mathrm{e}$ & 0,65 a c \\
\hline $\mathrm{n}$ & 6 & $43,5 \mathrm{bj}$ & 0,50 е о & 1.991 .799 a a & $20,8 \mathrm{ab}$ & $0,62 \mathrm{~b} \mathrm{c}$ & $3,31 \mathrm{bf}$ & 0,56 a d \\
\hline $\mathrm{o}$ & 7 & $63,1 \mathrm{a} \mathrm{c}$ & 0,76 a d & $1.328 .049 \mathrm{f} \mathrm{m}$ & $10,1 \mathrm{~b} \mathrm{~b}$ & $0,66 \mathrm{bc}$ & $3,42 \mathrm{~b} \mathrm{~d}$ & 0,58 a d \\
\hline i & 8 & 61,6 a d & $0,69 \mathrm{~b} \mathrm{~g}$ & 1.458 .194 e j & $9,1 \mathrm{~b} \mathrm{~b}$ & $0,61 \mathrm{bc}$ & $3,64 \mathrm{ab}$ & $0,50 \mathrm{a} \mathrm{e}$ \\
\hline $\begin{array}{l}n \\
h\end{array}$ & 9 & $35,4 \mathrm{~d} \mathrm{~m}$ & $0,58 \mathrm{~d} 1$ & $1.719 .645 \mathrm{~b} \mathrm{e}$ & $6,8 \mathrm{c} \mathrm{c}$ & $0,52 \mathrm{c} \mathrm{c}$ & $3,24 \mathrm{~b} \mathrm{f}$ & $0,48 \mathrm{a} \mathrm{e}$ \\
\hline $\begin{array}{l}11 \\
\mathrm{a}\end{array}$ & 10 & $45,3 \mathrm{~b} \mathrm{i}$ & $0,61 \mathrm{c} \mathrm{j}$ & $1.640 .596 \mathrm{c} \mathrm{g}$ & $13,0 \mathrm{~b} \mathrm{~b}$ & $0,56 \mathrm{~b} \mathrm{c}$ & $3,37 \mathrm{be}$ & $0,50 \mathrm{a} \mathrm{e}$ \\
\hline \multirow[t]{4}{*}{ s } & 11 & $45,4 \mathrm{~b} \mathrm{~h}$ & 0,73 a f & $1.376 .851 \mathrm{fl}$ & $14,5 \mathrm{~b} \mathrm{~b}$ & $0,64 \mathrm{~b} \mathrm{c}$ & $3,18 \mathrm{~b} \mathrm{f}$ & $0,61 \mathrm{ad}$ \\
\hline & 12 & $43,5 \mathrm{~b} \mathrm{j}$ & $0,61 \mathrm{c} \mathrm{k}$ & $1.640 .596 \mathrm{c} \mathrm{h}$ & $13,0 \mathrm{~b} \mathrm{~b}$ & $0,66 \mathrm{~b} \mathrm{c}$ & $3,13 \mathrm{~b} \mathrm{f}$ & $0,63 \mathrm{a} \mathrm{d}$ \\
\hline & Média & $41,8 \mathrm{~A}$ & $0,65 \mathrm{~A}$ & $1.553 .806 \mathrm{~A}$ & $13,3 \mathrm{~A}$ & $0,62 \mathrm{~A}$ & $3,20 \mathrm{~A}$ & $0,58 \mathrm{~A}$ \\
\hline & $\mathrm{CV}(\%)$ & 30,08 & 12,91 & 13,44 & 25,16 & 14,31 & 10,97 & 17,21 \\
\hline & 1 & $37,7 \mathrm{f} \mathrm{m}$ & $0,70 \mathrm{c} \mathrm{g}$ & $1.430 .170 \mathrm{bj}$ & $11,7 \mathrm{a} \mathrm{b}$ & $0,52 \mathrm{dc}$ & $3,12 \mathrm{c} \mathrm{f}$ & $0,50 \mathrm{c} \mathrm{e}$ \\
\hline M & 2 & $35,9 \mathrm{f} \mathrm{m}$ & 0,85 a a & $1.176 .555 \mathrm{c} \mathrm{f}$ & $16,6 \mathrm{ab}$ & $0,51 \mathrm{dc}$ & $3,26 \mathrm{~d} \mathrm{f}$ & $0,47 \mathrm{c} \mathrm{e}$ \\
\hline $\mathrm{a}$ & 3 & $42,7 \mathrm{~d} \mathrm{k}$ & $0,74 \mathrm{c} \mathrm{f}$ & $1.366 .378 \mathrm{~b} \mathrm{f}$ & $11,6 \mathrm{ab}$ & $0,67 \mathrm{~b} \mathrm{c}$ & $3,43 \mathrm{c} \mathrm{d}$ & $0,59 \mathrm{~b} \mathrm{~d}$ \\
\hline $\mathrm{r}$ & 4 & $44,9 \mathrm{c} \mathrm{i}$ & $0,66 \mathrm{dh}$ & $1.662 .802 \mathrm{~b} \mathrm{f}$ & $15,3 \mathrm{ab}$ & $0,64 \mathrm{c} \mathrm{c}$ & $2,86 \mathrm{fi}$ & $0,68 \mathrm{~b} \mathrm{c}$ \\
\hline c & 5 & $64,8 \mathrm{a} \mathrm{b}$ & $0,81 \mathrm{~b} \mathrm{f}$ & $1.241 .858 \mathrm{c} \mathrm{o}$ & $12,6 \mathrm{ab}$ & $0,70 \mathrm{~b} \mathrm{~b}$ & $3,38 \mathrm{c} \mathrm{e}$ & $0,63 \mathrm{~b} \mathrm{~d}$ \\
\hline í & 6 & 39,6 e m & $0,55 \mathrm{e} \mathrm{h}$ & $1.814 .291 \mathrm{a} \mathrm{c}$ & $8,8 \mathrm{ab}$ & $0,54 \mathrm{c} \mathrm{c}$ & $3,46 \mathrm{c} \mathrm{d}$ & $0,47 \mathrm{c} \mathrm{e}$ \\
\hline 1 & 7 & $44,1 \mathrm{c} \mathrm{j}$ & 0,60 e k & $1.668 .985 \mathrm{~b} \mathrm{f}$ & $11,0 \mathrm{ab}$ & $0,59 \mathrm{c} \mathrm{c}$ & $3,55 \mathrm{~b} \mathrm{c}$ & $0,50 \mathrm{c} \mathrm{e}$ \\
\hline \multirow{2}{*}{ o } & 8 & $34,7 \mathrm{~g} \mathrm{~m}$ & $0,66 \mathrm{~d} h$ & $1.511 .066 \mathrm{bj}$ & $11,6 \mathrm{ab}$ & $0,59 \mathrm{c} \mathrm{c}$ & $2,65 \mathrm{~h} \mathrm{k}$ & $0,67 \mathrm{~b} \mathrm{c}$ \\
\hline & 9 & $33,1 \mathrm{~h} \mathrm{~m}$ & 0,57 e m & $1.778 .403 \mathrm{a} \mathrm{d}$ & $14,2 \mathrm{ab}$ & $0,64 \mathrm{bc}$ & 2,37 h 1 & $0,65 \mathrm{bc}$ \\
\hline D & 10 & 71,7 a a & 0,57 e m & $1.767 .163 \mathrm{a} \mathrm{d}$ & $14,9 \mathrm{a} \mathrm{b}$ & $0,44 \mathrm{e} \mathrm{e}$ & 3,77 a a & $0,35 \mathrm{dg}$ \\
\hline i & 11 & $53,8 \mathrm{~b} \mathrm{f}$ & $0,63 \mathrm{~d} \mathrm{i}$ & $1.581 .711 \mathrm{~b} \mathrm{i}$ & $13,7 \mathrm{ab}$ & 0,73 a a & $2,73 \mathrm{~g} \mathrm{j}$ & $0,81 \mathrm{a} a$ \\
\hline $\mathrm{a}$ & 12 & $30,1 \mathrm{i} \mathrm{m}$ & $0,63 \mathrm{di}$ & $1.589 .214 \mathrm{~b} \mathrm{i}$ & $16,9 \mathrm{ab}$ & $0,65 \mathrm{~b} \mathrm{c}$ & $3,35 \mathrm{c} \mathrm{e}$ & $0,58 \mathrm{~b} \mathrm{~d}$ \\
\hline \multirow[t]{2}{*}{ s } & Média & $44,4 \mathrm{~A}$ & $0,66 \mathrm{~A}$ & $1.549 .050 \mathrm{~A}$ & $13,2 \mathrm{~A}$ & $0,60 \mathrm{~A}$ & $3,21 \mathrm{~A}$ & $0,57 \mathrm{~A}$ \\
\hline & $\mathrm{CV}(\%)$ & 33,22 & 17,06 & 17,38 & 23,51 & 18,57 & 12,41 & 25,07 \\
\hline \multirow{6}{*}{$\begin{array}{l}\mathrm{T} \\
\mathrm{r} \\
\hat{\mathrm{e}} \\
\mathrm{s}\end{array}$} & 1 & 44,1 e j & $0,66 \mathrm{eh}$ & $1.521 .335 \mathrm{ej}$ & $16,4 \mathrm{ab}$ & $0,55 \mathrm{a} \mathrm{c}$ & 3,60 a c & $0,46 \mathrm{~b} \mathrm{e}$ \\
\hline & 2 & $41,4 \mathrm{f} 1$ & $0,63 \mathrm{fi}$ & $1.587 .911 \mathrm{~d} \mathrm{i}$ & $15,0 \mathrm{ab}$ & $0,57 \mathrm{a} \mathrm{c}$ & $3,43 \mathrm{ad}$ & $0,51 \mathrm{~b} \mathrm{e}$ \\
\hline & 3 & $51,3 \mathrm{c} \mathrm{g}$ & $0,64 \mathrm{fh}$ & $1.571 .242 \mathrm{dj}$ & 22,3 a a & 0,68 a c & $3,55 \mathrm{a} \mathrm{c}$ & $0,57 \mathrm{~b} \mathrm{~d}$ \\
\hline & 4 & $32,1 \mathrm{~g} \mathrm{~m}$ & $0,71 \mathrm{dg}$ & $1.415 .209 \mathrm{~g} \mathrm{k}$ & $18,7 \mathrm{ab}$ & 0,68 a c & $3,54 \mathrm{a} \mathrm{c}$ & $0,57 \mathrm{~b} \mathrm{~d}$ \\
\hline & 5 & $44,6 \mathrm{dj}$ & $0,55 \mathrm{~h} \mathrm{n}$ & $1.835 .317 \mathrm{a} \mathrm{b}$ & $17,0 \mathrm{ab}$ & 0,58 a c & 3,09 a g & $0,57 \mathrm{~b} \mathrm{~d}$ \\
\hline & 6 & $38,5 \mathrm{f} \mathrm{m}$ & $0,75 \mathrm{c} \mathrm{e}$ & $1.342 .051 \mathrm{~h} \mathrm{~m}$ & $15,3 \mathrm{ab}$ & 0,63 a c & 3,29 a f & $0,57 \mathrm{~b} \mathrm{~d}$ \\
\hline B & 7 & $60,0 \mathrm{a} \mathrm{d}$ & $0,79 \mathrm{~b} \mathrm{c}$ & 1.274.247 h n & $11,9 \mathrm{ab}$ & $0,71 \mathrm{ab}$ & 3,27 a f & $0,66 \mathrm{~b} \mathrm{c}$ \\
\hline $\mathrm{a}$ & 8 & $26,5 \mathrm{~h} \mathrm{n}$ & $0,60 \mathrm{~g} \mathrm{k}$ & $1.682 .431 \mathrm{c} \mathrm{f}$ & $14,2 \mathrm{ab}$ & 0,67 a c & 3,35 a e & $0,61 \mathrm{~b} \mathrm{~d}$ \\
\hline $\mathrm{r}$ & 9 & $41,8 \mathrm{f} \mathrm{k}$ & 0,84 a a & $1.200 .615 \mathrm{i} \mathrm{p}$ & $12,8 \mathrm{ab}$ & $0,72 \mathrm{ab}$ & 3,14 a f & 0,68 a c \\
\hline $\mathrm{r}$ & 10 & $38,8 \mathrm{f} \mathrm{m}$ & $0,57 \mathrm{~g} \mathrm{~m}$ & $1.777 .992 \mathrm{~b} \mathrm{~d}$ & $11,8 \mathrm{a} b$ & $0,73 \mathrm{a} \mathrm{a}$ & 3,20 a f & $0,69 \mathrm{a} b$ \\
\hline $\mathrm{a}$ & 11 & $58,2 \mathrm{~b} \mathrm{e}$ & $0,67 \mathrm{e} \mathrm{h}$ & $1.504 .277 \mathrm{fj}$ & $10,2 \mathrm{ab}$ & 0,68 a c & $3,65 \mathrm{ab}$ & $0,56 \mathrm{~b} \mathrm{~d}$ \\
\hline \multirow[t]{3}{*}{$\mathrm{s}$} & 12 & $30,3 \mathrm{~h} \mathrm{~m}$ & $0,61 \mathrm{fk}$ & $1.676 .839 \mathrm{c} \mathrm{f}$ & $10,7 \mathrm{a} \mathrm{b}$ & $0,48 \mathrm{a} \mathrm{d}$ & 3,43 a d & $0,42 \mathrm{c} \mathrm{f}$ \\
\hline & Média & $42,3 \mathrm{~A}$ & $0,67 \mathrm{~A}$ & $1.532 .455 \mathrm{~A}$ & $14,7 \mathrm{~A}$ & $0,64 \mathrm{~A}$ & $3,38 \mathrm{~A}$ & $0,57 \mathrm{~A}$ \\
\hline & $\mathrm{CV}(\%)$ & 27,34 & 15,16 & 14,52 & 22,16 & 18,72 & 8,51 & 21,15 \\
\hline \multirow[t]{2}{*}{$3 \times 12$} & Média & 42,9 & 0,66 & 1545104 & 13,7 & 0,62 & 3,26 & 0,58 \\
\hline & $\mathrm{CV}(\%)$ & 30,33 & 15,08 & 15,11 & 20,98 & 17,42 & 10,91 & 21,21 \\
\hline
\end{tabular}

$\overline{\text { Médias seguidas de letras maiúsculas iguais nas colunas para população não diferem entre si estatisticamente pelo teste de Tukey a }}$ $5 \%$ de probabilidade. Minúsculas para árvores porta-sementes dentro da população e minúsculas em negrito para todas as portasementes não diferem entre si estatisticamente pelo teste de Scott-Knott a 5\% de probabilidade. CV: coeficiente de variação.

Em trabalho realizado por Ferriani et al. (2005), foi observado um peso de mil cipselas de $0,8 \mathrm{~g}$, correspondendo a 1.250 .000 cipselas. $\mathrm{kg}^{-1}$. Lorenzi (2001) cita que um quilograma de sementes contém aproximadamente 1.550.000 unidades, enquanto que Carvalho (1994) informa que varia de 1.300 .000 a 1.620.000 sementes. $\mathrm{kg}^{-1}$. para Seitz et al. (1976), o peso de mil cipselas está em torno de 0,78 g, e a quantidade de sementes por quilo varia entre 1.200 .000 e 1.300.000. O resultado demonstra o pequeno 
tamanho das sementes em relação à maioria das outras espécies florestais nativas, sugerindo um comportamento típico de árvores pioneiras e de sementes ortodoxas. O grande número de sementes por unidade de peso é uma característica que pode estar compensando sua baixa germinabilidade, que é auxiliada pela sua alta capacidade de dispersão, dada pela presença de estruturas que facilitam o vôo das cipselas (pápus). Figliolia et al. (1993) explicam que a variável número de sementes por quilograma fornece importante informação prática para os viveiristas, pois é o conhecimento do peso de cipselas que precisa ser colhido ou adquirido para uma determinada produção de mudas.

O peso das amostras de trabalho para análise de pureza de sementes exageradamente pequenas de espécies não relacionadas nas Regras para Análise de Sementes (BRASIL, 1992), como é o caso de Piptocarpha angustifolia, deve basear-se numa amostra contendo nunca menos que duas mil sementes, desde que não ultrapasse o peso mínimo de 0,1 g. Para espécies do gênero Eucalyptus, também com sementes muito pequenas, mas que constam nas referidas Regras para Análise de Sementes, são prescritos em torno de cinco gramas. São necessários então, pelo menos 1,29 gramas de cipselas de Piptocarpha angustifolia para compor uma amostra de trabalho para o teste de pureza.

Um fator característico de Piptocarpha angustifolia está relacionado ao baixo teor de água inicial das cipselas observado em todas as árvores porta-sementes e populações. Nota-se que somente duas médias foram superiores a $20 \%$ (20,8\% em Canoinhas e 22,3\% em Três Barras). As demais variaram predominantemente entre 11 e $16 \%$, mas atingiram menos de $10 \%$ em duas populações de Canoinhas $(9,1$ e 6,8\%) e uma de Marcílio Dias (8,8\%). Esses resultados determinam o comportamento estatístico em que não houve diferenças significativas nas populações Marcílio Dias e Três Barras. Apenas em Canoinhas foram constatadas diferenças significativas. As médias de teor de água das cipselas de Piptocarpha angustifolia foram, portanto, de 13,3\% em Canoinhas, 13,2\% em Marcílio Dias e 14,7\% em Três Barras, não diferindo significativamente.

É importante o conhecimento do teor de água inicial das cipselas para a manutenção de sua qualidade fisiológica, pois, segundo Silva (1988), será útil na decisão sobre o armazenamento, na proteção às injúrias mecânicas, na escolha do tempo e da temperatura de secagem e principalmente na comercialização. Confirmam Figliolia et al. (1993) e concordam Toledo; Marcos Filho (1977) que a determinação do teor de água é fundamental para a conservação da qualidade da semente e possibilita manejar corretamente o lote, aplicando medidas para manutenção da viabilidade e do vigor.

Em média, na população Canoinhas, as cipselas de Piptocarpha angustifolia apresentaram 0,62 $\mathrm{mm}$ de largura, 3,20 $\mathrm{mm}$ de comprimento e 0,58 $\mathrm{mm}$ de espessura. Em Marcílio Dias, 0,60 $\mathrm{mm}$ de largura, 3,21 mm de comprimento e 0,57 mm de espessura. Em Três Barras, 0,64 mm de largura, 3,38 $\mathrm{mm}$ de comprimento e $0,57 \mathrm{~mm}$ de espessura. Essas variáveis, que caracterizam a biometria das cipselas, não diferiram significativamente entre as populações, podendo-se definir como média geral para a espécie $0,62 \mathrm{~mm}$ de largura, $3,26 \mathrm{~mm}$ de comprimento e $0,58 \mathrm{~mm}$ de espessura. As variações internas das variáveis biométricas foram pequenas, mas significativas para largura e comprimento em Canoinhas e Marcílio Dias, porém as duas não diferiram significativamente em Três Barras. A espessura foi igual em Canoinhas, mas apresentou diferenças em Marcílio Dias e Três Barras. Ao se analisar todas as árvores porta-sementes, a biometria apresentou diferenças significativas para todas as variáveis.

Em trabalho realizado por Reitz et al. (1983), não são informadas as medidas das cipselas, mas no desenho em escala pode-se deduzir que algumas medidas observadas foram de aproximadamente $3,0 \mathrm{~mm}$ de comprimento e 0,4 mm de largura, enquanto Ferriani et al. (2005) informam que Piptocarpha angustifolia possui produção de imensa quantidade de sementes pequenas de baixo potencial germinativo, com $3 \mathrm{~mm}$, mas não informam a que dimensão estão se referindo - provavelmente diz respeito ao comprimento da cipsela. Seitz (1976) descreve mais detalhadamente a cipsela como em forma quase de coluna, com cerca de $3 \mathrm{~mm}$ de comprimento, indistintamente deca-costada, glabra e com diâmetro médio de $0,7 \mathrm{~mm}$.

\section{Qualidade fisiológica}

As porcentagens de germinação das cipselas de Piptocarpha angustifolia foram sempre muito baixas. Na população Canoinhas, os valores de germinação variaram de 4 a $8 \%$, sem diferenças significativas, com média de 6,08\%. Na população de Três Barras, variaram de 3 a 7\%, mas um lote não apresentou germinação e, em razão disso, foram observadas diferenças significativas para uma média de 4,83\% de germinação. Na população de Marcílio Dias, a árvore porta-sementes oito (com 16\%), a dois (com 11\%) e a quatro (com 10\%) melhoraram a germinação. As demais variaram entre 3 e 5\%, o que

FLORESTA, Curitiba, PR, v. 39, n. 2, p. 419-430, abr./jun. 2009. 
determinou diferenças significativas, com destaque para a árvore que apresentou $16 \%$, em segundo as de 10 e $11 \%$ e as demais em um nível inferior, mas a média ficou próxima das populações anteriores, em 6\%. Essas médias não diferiram significativamente entre as populações, mas mostraram pequenas diferenças estatísticas entre todas as árvores porta-sementes (Tabela 2).

Vários trabalhos de diferentes autores com plantas da família Asteraceae já acusavam baixa germinação das suas sementes, como os de Seitz (1976), que relata resultados dos testes com Helenium amarum (bitterweed) e Lactuca sativa (alface). Da mesma forma, Beskow; Harrington (2005) relataram experimentos testando germinação de sementes do gênero Senecio, Davide; Tonetti (2003a) com Eremanthus incanus (candeião) e Davide; Tonetti (2003b) com Eremanthus erythropappus (candeia).

Carvalho (1994) lembra que a produção de sementes é de aproximadamente $10 \%$ em relação ao número de flores, afirmando que a espécie possui baixa germinação, apresentando em torno de 10 a $20 \%$ de sementes viáveis. Seitz (1976) explica que, em cipselas não germinadas, os óvulos não se encontram desenvolvidos e que, portanto, não são encontradas sementes. Lorenzi (2001) relata que sementes dessa espécie apresentam baixa germinação, entretanto não cita valores. Ferriani et al. (2005) obtiveram 5,5 a 7,5\% de germinação em sementes de Piptocarpha angustifolia em seu experimento.

Os IVGs dos lotes também apresentaram altos coeficientes de variação e se detectaram diferenças significativas entre as médias dentro das três populações. O tG variou de um mínimo de 20 até 37 dias, porém as populações Canoinhas e Marcílio Dias não diferiram significativamente. Em Três Barras, devido a um lote que não germinou, a diferença apareceu dentro da população. Entre todas as árvores porta-sementes, também houve diferenças significativas, com médias de 26, 24 e 26 dias, respectivamente, para Canoinhas, Marcílio Dias e Três Barras, enquanto as populações se equivaleram estatisticamente (Figura 1). A velocidade média, por consequência, apresentou o mesmo comportamento.

Carvalho (1994), além de citar que as cipselas são pequenas e com baixa relação semente germinada/cipsela, informa que o período de germinação inicia entre 6 a 60 dias após a semeadura. Seitz (1976) observou $37 \%$ de germinação, iniciando-se aos cinco dias de início do teste e completando-se após onze dias.

Analisando-se as variáveis de emergência, as médias de porcentagem de emergência variaram de 1 a $8 \%$ em Canoinhas, com média de 5,25\%, apresentando diferença significativa. Variaram de 2 a $15 \%$ em Marcílio Dias, com média de 5,67\%, também apresentando diferenças significativas dentro da população, com destaque para duas árvores com 15 e $10 \%$ de emergência, sendo superiores às demais. Em Três Barras, dois lotes não apresentaram emergência das cipselas, mas as demais, entre 5 e 9\%, não diferiram. Entre todas as porta-sementes, também se constatou a homogeneidade observada, mas houve diferenças estatísticas, devido aos dois lotes que não apresentaram emergência das cipselas. Assim, por consequência, não se detectaram diferenças entre populações para essa variável.

O IVE foi mais enfático nesse comportamento, não apresentando nenhuma diferença estatística dentro das populações, com exceção de Três Barras, que teve dois lotes não emergidos. Entre todas as árvores porta-sementes o comportamento foi idêntico ao encontrado na população de Três Barras, e entre populações não se encontraram diferenças, com médias de 0,01871, 0,01983 e 0,01728 para Canoinhas, Marcílio Dias e Três Barras, respectivamente. A média geral foi de 0,01861. Quanto ao tempo médio de germinação, os coeficientes de variação foram muito baixos, diferentemente das demais variáveis de germinação, emergência e vigor. Pequenas diferenças significativas dentro das populações foram constatadas em Canoinhas e Marcílio Dias (as duas de 68 a 78 dias), mas em Três Barras não houve diferenças, com médias de 71 dias nas três populações, também sem diferenças entre elas. Quando se consideraram todas as árvores porta-sementes, apareceram pequenas diferenças significativas (Figura 1). A velocidade média de emergência foi uma das variáveis mais homogêneas. Em quase todos os casos, as diferenças significativas não apareceram, somente para os dois lotes não emergidos em Três Barras. Houve igualdade em velocidade de emergência, dentro das populações Canoinhas e Marcílio Dias, entre as cipselas de árvores porta-sementes, com exceção daqueles dois lotes, e também igualdade entre as populações. Segundo Lorenzi (2001), a emergência ocorre em 15-25 dias, e Seitz (1976) concluiu que a germinação é rápida, não havendo necessidade de tratamentos pré-germinativos.

Importante salientar que as baixas germinações e emergências esperadas para a espécie se confirmaram e já possuem motivos comprovados pela pesquisa (SEITZ et al., 1976). Conforme foi observado nessas amostras e segundo o que informa a literatura, embora as árvores porta-sementes de Piptocarpha angustifolia, como as demais da família Asteraceae, produzam grandes quantidades de 
sementes em seus capítulos, o exame deles mostrou que haviam inúmeras cipselas sem semente viável, ou seja, sem embrião ou com embrião abortado, ou ainda cipselas vazias ou incompletas.

Tabela 2. Médias de germinação, emergência e índices de vigor de cipselas de árvores porta-sementes em populações de Piptocarpha angustifolia no planalto norte catarinense.

Table 2. Germination, emergence and vigor indices averages of the seeds of seed-bearer trees of Piptocarpha angustifolia populations in Santa Catarina north plateau.

\begin{tabular}{|c|c|c|c|c|c|c|c|c|c|}
\hline \multicolumn{2}{|c|}{$\begin{array}{l}\text { Populações e } \\
\text { porta-sementes }\end{array}$} & $\begin{array}{c}\mathbf{G} \\
(\%)\end{array}$ & IVG & $\begin{array}{c}\mathbf{t G} \\
\text { (dias) }\end{array}$ & VG & $\begin{array}{c}\mathrm{E} \\
(\%)\end{array}$ & IVE & $\begin{array}{c}\mathrm{tE} \\
\text { (dias) }\end{array}$ & VE \\
\hline \multirow[b]{4}{*}{$\mathrm{C}$} & 1 & $8 \mathrm{ab}$ & $0,08 \mathrm{~b} \mathrm{~b}$ & $27 \mathrm{ab}$ & $0,04 \mathrm{a} a$ & $1 \mathrm{~b} \mathrm{a}$ & $0,00 \mathrm{a} a$ & $78 \mathrm{a} a$ & $0,01 \mathrm{a} a$ \\
\hline & 2 & $6 a b$ & $0,07 \mathrm{~b} b$ & $22 \mathrm{ac}$ & $0,05 \mathrm{a} a$ & $4 \mathrm{a} a$ & $0,01 \mathrm{a} a$ & $70 \mathrm{c} \mathrm{d}$ & $0,01 \mathrm{a} \mathrm{a}$ \\
\hline & 3 & $8 \mathrm{ab}$ & $0,09 \mathrm{~b} \mathrm{~b}$ & $27 \mathrm{ab}$ & $0,04 \mathrm{a} a$ & $6 \mathrm{a} a$ & $0,02 \mathrm{a} a$ & $69 \mathrm{c} \mathrm{e}$ & $0,01 \mathrm{a} \mathrm{a}$ \\
\hline & 4 & $6 \mathrm{ab}$ & $0,07 \mathrm{~b} \mathrm{~b}$ & 25 a c & $0,04 \mathrm{a}$ a & 5 a a & $0,02 \mathrm{a} a$ & $69 \mathrm{c} \mathrm{e}$ & $0,01 \mathrm{a} a$ \\
\hline $\begin{array}{l}\mathrm{a} \\
\mathrm{n}\end{array}$ & 5 & $7 \mathrm{ab}$ & $0,06 \mathrm{~b} \mathrm{~b}$ & $33 \mathrm{a} \mathrm{a}$ & $0,03 \mathrm{a} a$ & $5 \mathrm{a} a$ & $0,02 \mathrm{a} a$ & $69 \mathrm{c} \mathrm{e}$ & $0,01 \mathrm{a} a$ \\
\hline o & 6 & $8 \mathrm{ab}$ & $0,10 \mathrm{a} b$ & $20 \mathrm{a} \mathrm{c}$ & $0,05 \mathrm{a} a$ & $5 \mathrm{a} a$ & $0,02 \mathrm{a} a$ & $71 \mathrm{c} \mathrm{c}$ & $0,01 \mathrm{a} a$ \\
\hline $\mathrm{i}$ & 7 & $4 \mathrm{ac}$ & $0,04 \mathrm{~b} \mathrm{c}$ & 23 a c & $0,04 \mathrm{a} a$ & $5 \mathrm{a} a$ & $0,02 \mathrm{a} a$ & $68 \mathrm{c} \mathrm{e}$ & $0,01 \mathrm{a} \mathrm{a}$ \\
\hline \multirow{7}{*}{$\begin{array}{l}\mathrm{n} \\
\mathrm{h} \\
\mathrm{a} \\
\mathrm{s}\end{array}$} & 8 & $7 \mathrm{ab}$ & $0,07 \mathrm{~b} b$ & $32 \mathrm{a} a$ & $0,03 \mathrm{a} a$ & $6 \mathrm{a} a$ & $0,02 \mathrm{a} a$ & $70 \mathrm{c} \mathrm{c}$ & $0,01 \mathrm{a} \mathrm{a}$ \\
\hline & 9 & $5 \mathrm{ab}$ & $0,06 \mathrm{~b} \mathrm{~b}$ & $20 \mathrm{ac}$ & $0,05 \mathrm{a} a$ & $6 \mathrm{a} a$ & $0,02 \mathrm{a} a$ & $71 \mathrm{c} \mathrm{c}$ & $0,01 \mathrm{a} \mathrm{a}$ \\
\hline & 10 & $4 \mathrm{ac}$ & $0,03 \mathrm{c} \mathrm{c}$ & $35 \mathrm{a} a$ & $0,03 \mathrm{a} a$ & 8 a a & $0,03 \mathrm{a} a$ & $72 \mathrm{~b} \mathrm{c}$ & $0,01 \mathrm{a} \mathrm{a}$ \\
\hline & 11 & $6 \mathrm{ab}$ & $0,06 \mathrm{~b} \mathrm{~b}$ & $25 \mathrm{a} \mathrm{c}$ & $0,04 \mathrm{a} a$ & $6 \mathrm{a} a$ & $0,02 \mathrm{a} a$ & $70 \mathrm{~cd}$ & $0,01 \mathrm{a} a$ \\
\hline & 12 & $4 \mathrm{a} \mathrm{c}$ & $0,05 \mathrm{~b} \mathrm{c}$ & $20 \mathrm{ac}$ & $0,05 \mathrm{a} a$ & $6 \mathrm{a} a$ & $0,02 \mathrm{a} a$ & $72 \mathrm{~b} \mathrm{c}$ & $0,01 \mathrm{a} a$ \\
\hline & Média & $6, A$ & $0,07 \mathrm{~A}$ & $26 \mathrm{~A}$ & $0,03 \mathrm{~A}$ & $5 \mathrm{~A}$ & $0,02 \mathrm{~A}$ & $71 \mathrm{~A}$ & $0,01 \mathrm{~A}$ \\
\hline & $\mathrm{CV}(\%)$ & 35,40 & 32,92 & 30,86 & 33,90 & 37,52 & 76,77 & 5,00 & 28,85 \\
\hline \multirow[b]{2}{*}{ M } & 1 & $5 \mathrm{cb}$ & $0,05 b \mathrm{c}$ & $27 \mathrm{ab}$ & $0,04 \mathrm{a} a$ & $6 \mathrm{ba}$ & $0,02 \mathrm{a} a$ & $78 \mathrm{ab}$ & $0,01 \mathrm{a} \mathrm{a}$ \\
\hline & 2 & $11 \mathrm{bb}$ & $0,13 \mathrm{~b} \mathrm{~b}$ & 23 a c & $0,05 \mathrm{a} \mathrm{a}$ & $6 \mathrm{~b} \mathrm{a}$ & $0,02 \mathrm{a} \mathrm{a}$ & $71 \mathrm{~b} \mathrm{c}$ & $0,01 \mathrm{a} \mathrm{a}$ \\
\hline $\mathrm{a}$ & 3 & $4 \mathrm{c} \mathrm{c}$ & $0,04 \mathrm{c} \mathrm{c}$ & $27 \mathrm{ab}$ & $0,04 \mathrm{a}$ a & $5 \mathrm{~b} a$ & $0,02 \mathrm{a} a$ & $72 \mathrm{~b} \mathrm{c}$ & $0,01 \mathrm{a} a$ \\
\hline $\mathrm{r}$ & 4 & $10 \mathrm{~b} \mathrm{~b}$ & $0,11 \mathrm{~b} \mathrm{~b}$ & $27 \mathrm{ab}$ & 0,04 a a & $10 \mathrm{a} \mathrm{a}$ & 0,04 a a & $70 \mathrm{bc}$ & 0,01 a a \\
\hline $\mathrm{c}$ & 5 & $4 \mathrm{cc}$ & $0,04 \mathrm{c} \mathrm{c}$ & $27 \mathrm{ab}$ & 0,04 a a & $3 \mathrm{~b} a$ & $0,01 \mathrm{a}$ a & $71 \mathrm{~b} \mathrm{c}$ & $0,01 \mathrm{a} a$ \\
\hline $\begin{array}{l}1 \\
1\end{array}$ & 6 & $5 \mathrm{cb}$ & $0,06 \mathrm{~b} \mathrm{c}$ & $27 \mathrm{ab}$ & $0,04 \mathrm{a} \mathrm{a}$ & $3 \mathrm{~b} \mathrm{a}$ & $0,01 \mathrm{a} \mathrm{a}$ & $71 \mathrm{~b} \mathrm{c}$ & $0,01 \mathrm{a} \mathrm{a}$ \\
\hline $\mathrm{l}$ & 7 & $3 \mathrm{cc}$ & $0,04 \mathrm{c} \mathrm{c}$ & 20 a c & $0,05 \mathrm{a} \mathrm{a}$ & $3 \mathrm{~b}$ a & $0,01 \mathrm{a} \mathrm{a}$ & $71 \mathrm{~b} \mathrm{c}$ & $0,01 \mathrm{a} \mathrm{a}$ \\
\hline \multirow{2}{*}{$\begin{array}{l}1 \\
0\end{array}$} & 8 & 16 a a & 0,19 a a & 22 a c & $0,05 \mathrm{a} a$ & $15 \mathrm{a} \mathrm{a}$ & 0,05 a a & $71 \mathrm{~b} \mathrm{c}$ & $0,01 \mathrm{a} a$ \\
\hline & 9 & $4 \mathrm{c} \mathrm{c}$ & $0,04 \mathrm{c} \mathrm{c}$ & $27 \mathrm{ab}$ & $0,04 \mathrm{a} \mathrm{a}$ & $4 \mathrm{~b}$ a & $0,01 \mathrm{a} \mathrm{a}$ & $70 \mathrm{c} \mathrm{c}$ & $0,01 \mathrm{a} a$ \\
\hline D & 10 & $3 \mathrm{cc}$ & $0,04 \mathrm{c} \mathrm{c}$ & $20 \mathrm{ac}$ & $0,05 \mathrm{a} a$ & $2 \mathrm{~b} \mathrm{a}$ & $0,01 \mathrm{a} a$ & $68 \mathrm{c} \mathrm{e}$ & $0,01 \mathrm{a} \mathrm{a}$ \\
\hline \multirow{2}{*}{$\begin{array}{l}\mathrm{i} \\
\mathrm{a}\end{array}$} & 11 & $3 \mathrm{cc}$ & $0,04 \mathrm{c} \mathrm{c}$ & $20 \mathrm{ac}$ & $0,05 \mathrm{a} \mathrm{a}$ & $6 \mathrm{~b} \mathrm{a}$ & $0,02 \mathrm{a} \mathrm{a}$ & $72 \mathrm{~b} \mathrm{c}$ & $0,01 \mathrm{a} a$ \\
\hline & 12 & $4 \mathrm{cc}$ & $0,05 \mathrm{~b} \mathrm{c}$ & $20 \mathrm{ac}$ & $0,05 \mathrm{a} a$ & $5 \mathrm{~b} a$ & $0,02 \mathrm{a} a$ & $73 \mathrm{~b} \mathrm{c}$ & $0,01 \mathrm{a} \mathrm{a}$ \\
\hline \multirow[t]{2}{*}{ s } & Média & $6 \mathrm{~A}$ & $0,07 \mathrm{~A}$ & $24 \mathrm{~A}$ & $0,03 \mathrm{~A}$ & $6 \mathrm{~A}$ & $0,02 \mathrm{~A}$ & $71 \mathrm{~A}$ & $0,01 \mathrm{~A}$ \\
\hline & $\mathrm{CV}(\%)$ & 39,82 & 43,13 & 28,71 & 33,99 & 35,21 & 126,01 & 4,90 & 39,34 \\
\hline \multirow{6}{*}{$\begin{array}{l}\mathrm{r} \\
\hat{\mathrm{e}} \\
\mathrm{s}\end{array}$} & 1 & $5 \mathrm{ab}$ & $0,06 \mathrm{a} \mathrm{c}$ & $23 \mathrm{dc}$ & $0,04 \mathrm{~b} a$ & $6 \mathrm{a} \mathrm{a}$ & $0,02 \mathrm{a} a$ & $73 \mathrm{ac}$ & $0,01 \mathrm{a} \mathrm{a}$ \\
\hline & 2 & $0 \mathrm{bc}$ & $0,00 \mathrm{~b} \mathrm{c}$ & $0 \mathrm{fd}$ & $0,00 \mathrm{c} \mathrm{b}$ & 5 a a & $0,02 \mathrm{a} \mathrm{a}$ & 70 a d & $0,01 \mathrm{a} a$ \\
\hline & 3 & 3 a c & $0,03 \mathrm{a} \mathrm{c}$ & $35 \mathrm{~b} a$ & $0,03 \mathrm{~b}$ a & $5 \mathrm{a} a$ & $0,02 \mathrm{a} a$ & 70 a d & $0,01 \mathrm{a} \mathrm{a}$ \\
\hline & 4 & $4 \mathrm{ac}$ & $0,04 \mathrm{a} \mathrm{c}$ & $30 \mathrm{c} \mathrm{a}$ & $0,04 \mathrm{~b}$ a & $9 \mathrm{a} a$ & $0,03 \mathrm{a} a$ & $72 \mathrm{a} \mathrm{c}$ & $0,01 \mathrm{a} \mathrm{a}$ \\
\hline & 5 & $5 \mathrm{ab}$ & 0,05 a c & $24 \mathrm{c} \mathrm{c}$ & $0,04 \mathrm{~b}$ a & $5 \mathrm{a} a$ & $0,02 \mathrm{a} \mathrm{a}$ & 71 a c & $0,01 \mathrm{a} \mathrm{a}$ \\
\hline & 6 & $5 \mathrm{ab}$ & 0,04 a c & $37 \mathrm{a} \mathrm{a}$ & $0,03 \mathrm{~b}$ a & $0 \mathrm{bb}$ & $0,00 \mathrm{~b} b$ & $71 \mathrm{a} \mathrm{c}$ & $0,00 \mathrm{~b} \mathrm{~b}$ \\
\hline \multirow{8}{*}{$\begin{array}{l}\mathrm{B} \\
\mathrm{a} \\
\mathrm{r} \\
\mathrm{r} \\
\mathrm{a} \\
\mathrm{s}\end{array}$} & 7 & 4 a c & 0,03 a c & 37 a a & $0,03 \mathrm{~b}$ a & $6 \mathrm{a} a$ & $0,02 \mathrm{a} a$ & 73 a c & $0,01 \mathrm{a} a$ \\
\hline & 8 & $7 \mathrm{ab}$ & $0,09 \mathrm{a} \mathrm{b}$ & $20 \mathrm{ec}$ & $0,05 \mathrm{a} a$ & $0 \mathrm{bb}$ & $0,00 \mathrm{~b} b$ & 71 a c & $0,00 \mathrm{~b} \mathrm{~b}$ \\
\hline & 9 & $7 \mathrm{ab}$ & $0,08 \mathrm{a} \mathrm{b}$ & $23 \mathrm{dc}$ & $0,05 \mathrm{a} a$ & $6 \mathrm{a} a$ & $0,02 \mathrm{a} \mathrm{a}$ & $72 \mathrm{a} \mathrm{c}$ & $0,01 \mathrm{a} \mathrm{a}$ \\
\hline & 10 & $7 \mathrm{ab}$ & 0,06 a c & $34 \mathrm{~b} a$ & $0,03 \mathrm{~b} a$ & $7 \mathrm{a} a$ & $0,02 \mathrm{a} a$ & $71 \mathrm{ac}$ & $0,01 \mathrm{a} a$ \\
\hline & 11 & $7 \mathrm{ab}$ & $0,07 \mathrm{a} \mathrm{b}$ & $29 \mathrm{c} \mathrm{b}$ & $0,04 \mathrm{~b}$ a & $5 \mathrm{a} a$ & $0,02 \mathrm{a} \mathrm{a}$ & 70 a d & $0,01 \mathrm{a} \mathrm{a}$ \\
\hline & 12 & $4 \mathrm{ac}$ & $0,04 \mathrm{a} \mathrm{c}$ & $23 \mathrm{dc}$ & $0,04 \mathrm{~b}$ a & $5 \mathrm{a} \mathrm{a}$ & $0,02 \mathrm{a} \mathrm{a}$ & $70 \mathrm{a} \mathrm{d}$ & $0,01 \mathrm{a} \mathrm{a}$ \\
\hline & Média & $4 \mathrm{~A}$ & $0,05 \mathrm{~A}$ & $26 \mathrm{~A}$ & $0,03 \mathrm{~A}$ & $5 \mathrm{~A}$ & $0,02 \mathrm{~A}$ & $71 \mathrm{~A}$ & $0,01 \mathrm{~A}$ \\
\hline & $\mathrm{CV}(\%)$ & 38,60 & 31,41 & 41,42 & 32,96 & 32,36 & 31,82 & 3,86 & 31,86 \\
\hline \multirow{2}{*}{$3 \times 12$} & Média & 6 & 0,06 & 25 & 0,03 & 5 & 0,02 & 71 & 0,01 \\
\hline & $\mathrm{CV}(\%)$ & 39,18 & 39,50 & 34,48 & 32,98 & 39,62 & 38,59 & 4,61 & 32,23 \\
\hline
\end{tabular}

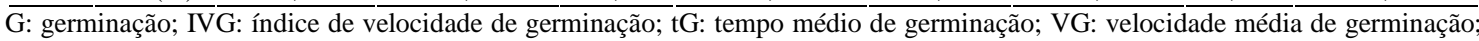
E: emergência; IVE: índice de velocidade de emergência; tE: tempo médio de emergência; VE: velocidade média de emergência; CV: coeficiente de variação. Médias seguidas de letras maiúsculas iguais nas colunas para população não diferem entre si estatisticamente pelo teste de Tukey a $5 \%$ de probabilidade. Minúsculas para árvores porta-sementes dentro da população e minúsculas em negrito para todas as porta-sementes não diferem entre si estatisticamente pelo teste de Scott-Knott a $5 \%$ de probabilidade. Os dados $\% \mathrm{G}, \mathrm{IVG}, \mathrm{VG}, \% \mathrm{E}$, IVE e VE foram transformados para $\sqrt{\mathrm{x}}+1$ para a análise estatística. 


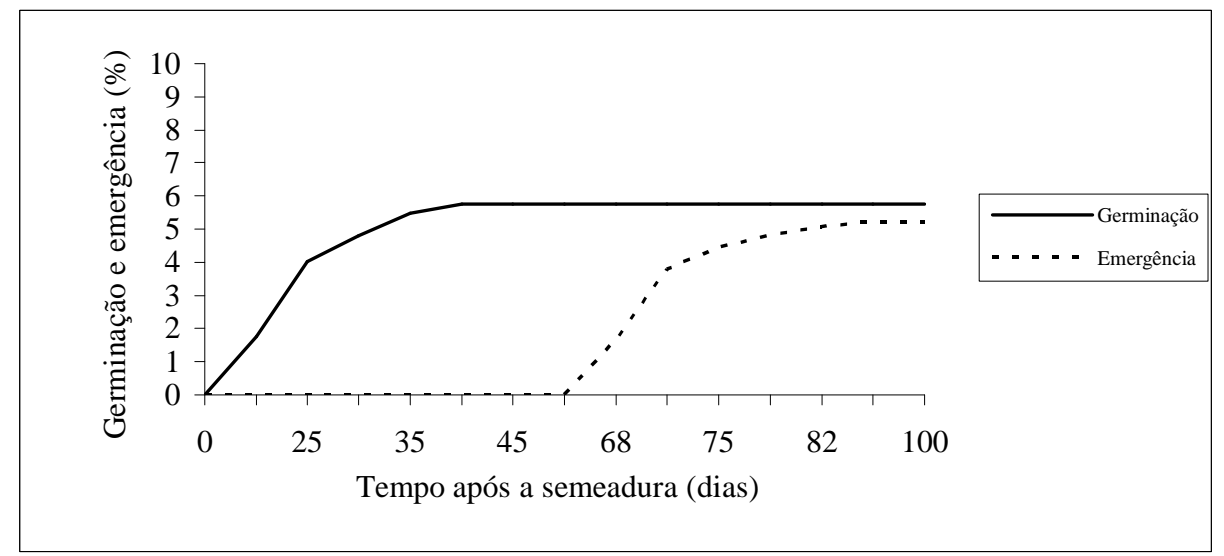

Figura 1. Porcentagem média acumulada de germinação e emergência de cipselas de Piptocarpha angustifolia considerando-se todas as populações e árvores porta-sementes.

Figure 1. Germination and emergence cumulative average percentage of Piptocarpha angustifolia seeds considering all populations and seed-bearer trees.

As germinações em laboratório se equivaleram às emergências em viveiro, apresentando valores semelhantes, porém o vigor das cipselas de Piptocarpha angustifolia se mostrou menor quando semeadas em sementeiras na estufa, o que foi demonstrado pelos menores IVEs e VEs e maior tE do que os índices de vigor da germinação (IVG, VG e tG). Tanto num ambiente como no outro, a germinação foi igual à emergência, porém, em laboratório, as cipselas germinaram com maior velocidade ou menor tempo do que em viveiro. Figliolia et al. (1993) mencionam que os testes de germinação realizados em laboratório sob condições consideradas ideais diminuem efeitos que possam interferir no máximo potencial de germinação. Já os testes de emergência em estufas, sob poucas condições controladas, são válidos em trabalhos de pesquisa, mas não são padronizados, podendo por esse motivo não estar próximos das condições ideais e afetarem para menos o vigor das cipselas.

\section{CONCLUSÕES}

- Para o teste de pureza, são necessárias amostras de trabalho de pelo menos $1,29 \mathrm{~g}$ de cipselas.

- A espécie possui em média 1.545 .104 cipselas por quilograma a $13,73 \%$ de teor de água, valores que diferiram entre árvores porta-sementes, independentemente da população.

- As cipselas mediram, em média, 0,62 $\mathrm{mm}$ de largura, 3,26 $\mathrm{mm}$ de comprimento e 0,58 $\mathrm{mm}$ de espessura, dimensões que diferem conforme a árvore porta-sementes, independentemente da população.

- A germinação variou de 0 a $16 \%$, com média de 5,64\%, independentemente da árvore porta-sementes e da população, sendo necessários 45 dias para o teste de germinação.

- A germinação iniciou aos 20 dias e se estendeu até 40 dias, com tempo médio de 25 dias, diferindo conforme a árvore porta-sementes, independentemente da população.

- A emergência das plântulas variou de 0 a $15 \%$, com média de 5,28\%.

- A emergência das plântulas iniciou aos 68 dias e se estendeu até 85 dias, com tempo médio de 71 dias, apresentando diferenças entre árvores porta-sementes e homogeneidade entre populações.

\section{REFERÊNCIAS}

BESKOW, W. B.; HARRINGTON, K. C. Influence of light on the germination of ragwort (Senecio jacobaea L., Asteraceae) seeds previously stored in the soil seed bank of a pasture. Revista Brasileira de Agrociência, Pelotas, v. 11, n. 3, p. 285-289, jul./set. 2005. 
BRASIL. Ministério da Agricultura e da Reforma Agrária. Regras para análise de sementes. Brasília, DF: SNAD, DNDV, CLAV, 1992. 365 p.

CARNEIRO, J. G. de A. Curso de silvicultura I. Curitiba: FUPEF, 1986. 131 p.

CARVALHO, P. E. R. Espécies florestais brasileiras. Colombo: Embrapa-CNPF 1994. 639 p.

DAVIDE, A. C.; TONETTI, O. A. O. Germinação de sementes de Eremanthus erythropapus (candeia) sob dois regimes de temperatura e luz. Informativo ABRATES, Londrina, v. 13, n. 3, p. 335, setembro, 2003b. (Edição Especial XIII Congresso Brasileiro de Sementes).

EMBRAPA. Sistema brasileiro de classificação de solos. Rio de Janeiro, 1999. 412 p.

EPAGRI. Estação meteorológica de Major Vieira. Dados históricos. Florianópolis: EPAGRI/CLIMERH, 2006. (Epagri, Boletim,14).

FERRIANI, A. P.; BORTOLINI, M. F.; NOGUEIRA, A. C. Comportamento germinativo de sementes de vassourão-branco (Piptocarpha angustifolia Dusén) sob diferentes temperaturas e substratos. Informativo ABRATES, Londrina, v. 15, n. 1, 2, 3, p. 585, ago. 2005. (Edição especial em CD do XIV Congresso Brasileiro de Sementes).

FIGLIOLIA, M. B.; OLIVEIRA, E. de C.; PIÑA-RODRIGUES, F. C. M. Análise de sementes. In: Aguiar, I. B. de; Piña-Rodrigues, F. C. M.; Figliolia, M. B. Sementes florestais tropicais. Brasília, DF: ABRATES, 1993. p. 137-174.

FLOSS, E. L. Fisiologia das plantas cultivadas: o estudo que está por trás do que se lê. Passo Fundo: UPF, 2004. $536 \mathrm{p}$.

IBGE - Instituto Brasileiro de Geografia e Estatística. Manual técnico da vegetação brasileira. Rio de Janeiro : IBGE, 1992. (Série manuais técnicos em geociências, n.1).

INOUE, M. T.; KUNYOSHI, Y. S.; RODERJAN, C. V. Projeto madeira do Paraná. Curitiba: FUPEF, 1984. $260 \mathrm{p}$.

KUNIYOSHI, Y. S. Morfologia da semente e da germinação de 25 espécies arbóreas de uma floresta com Araucária. 232 f. Dissertação (Mestrado em Ciências Florestais), Universidade Federal do Paraná, Curitiba: 1983.

LABOURIAU, L. G.; VALADARES, M. E. B. On the germination of seeds Calotropis procera (Ait.) Ait.f. Anais da Academia Brasileira de Ciências, Rio de Janeiro, v. 48, n. 2, p. 263-284, 1976.

LORENZI, H. Árvores brasileiras: manual de identificação e cultivo de plantas arbóreas do Brasil. 4. ed. Nova Odessa: Instituto Plantarum, 2001. v.1.

OLIVEIRA, O. dos S. Tecnologia de sementes florestais. Curitiba: Imprensa Universitária, 2007. 185 p.

PIMENTEL GOMES, F. P. Curso de estatística experimental. Piracicaba: ESALQ/USP, 1982. 186 p.

REITZ, R.; KLEIN, R. M.; REIS, A. Projeto Madeira de Santa Catarina. Florianópolis: Lunardelli, 1979. $320 \mathrm{p}$.

REITZ, R.; KLEIN, R. M.; REIS, A. Projeto Madeira do Rio Grande do Sul. Itajaí: Herbário Barbosa Rodrigues, 1983. 525 p. (Sellowia. Anais Botânicos, 34-35).

RIZZINI, C. T. Árvores e madeiras úteis do Brasil: manual de dendrologia brasileira. São Paulo: E. Blücher, 1971. $304 \mathrm{p}$.

ROTTA, E. Identificação dendrológica do Parque Municipal da Barreirinha, Curitiba-PR (baseada em características macromorfológicas). 271 f. Dissertação (Mestrado em Ciências Florestais) Universidade Federal do Paraná, Curitiba, 1977. 
SALOMÃO, A. N.; SOUSA-SILVA, J. C.; DAVIDE, A. C.; GONZÁlES, S.; TORRES, R. A. A.; WETZEL, M. M. V. S.; FIRETTI, F.; CALDAS, L. S. Germinação de sementes e produção de mudas de plantas do cerrado. Brasília, DF: Rede de Sementes do Cerrado, 2003. 96 p.

SCHIMIDT, L. Guide to handling of tropical and subtropical forest seed. Humlebaek: Danida Forest Seed Centre, 2000. 511 p.

SEITZ, R. A. Algumas características ecológicas e silviculturais do vassourão-branco (Piptocarpha angustifolia Dusén). 114 f. Dissertação (Mestrado em Ciências Florestais), Universidade Federal do Paraná, Curitiba: 1976.

SILVA, E. M. N. da. Determinação da umidade. In: Piña-Rodrigues, F. C. M. (Coord.). Manual de análise de sementes florestais. Campinas: Fundação Cargill, 1988. p. 60-69.

TOLEDO, F. F.; MARCOS FILHO, J. Manual das sementes: tecnologia da produção. São Paulo: Agronômica Ceres, 1977. 224 p.

VIEIRA, R. D.; CARVALHO, N. M. de. Testes de vigor em sementes. Jaboticabal: FUNEP/UNESP, 1994. $164 \mathrm{p}$. 